There is a need for research to focus on understudied LGBTQI+ cancer survivors, including GSD women. To date, research on sexual and gender minority women with cancer has focused almost exclusively on the experiences of cisgender lesbians with breast cancer. Non-normative relationships with femininity and categories of womanhood and gender performance have been shown to significantly affect how GSD women experience and make sense of cancer. However, work in the area of cancer and sexuality largely tends to assume cisgender embodiment, identity and expression. There are few studies available that specifically address trans and gender nonconforming women's experiences of cancer care.

Methods The research takes a mixed methods approach, including: open-ended survey data, 38 semi-structured interviews, and 15 follow-up Photovoice interviews with GSD women who have had cancer and their carers. Participants are selected across cancer type, and range from ages 18-92. Data is analysed using thematic decomposition analysis.

Results While data collection is on-going, this paper will focus on some key emergent themes amongst GSD women with cancer and their carers, including: heterosexism in cancer care; the impact of health care provider and health setting interactions on experiences of gendered embodiment; and ideal services and support.

\section{LOOKING FOR KATHY ACKER LOOKING FOR TRUST}

P Tzouva, Tom Voets. KU Leuven, Belgium

10.1136/bmjopen-2021-QHRN.32

Kathy Acker died of breast cancer. To convey her experience with medical care and personal confrontation with death, the experimental writer and intermedia artist left us Eurydice in the Underworld. It was the last story she wrote and in the very first page, Acker discloses that the creature she trusted was a black wolf. The wolf would never abandon her, 'whatever she does or whatever has happened to her' (1998:2). Eurydice (the persona Acker takes on) moves in a universe populated by a lover, random sexual partners, people she meets at what seems like a surrealist, last pilgrimage, and most notably, health professionals who are there to help her. Nevertheless, she makes such a statement of trust for nobody else. Acker affirmed that she wanted to leave a testimony: 'to describe as exactly as possible what it is like to experience conventional cancer medicine' but noted that she was still 'omitting the more horrific details' (1997:2). For all that, her complex, mixed-genre narrative succeeds in confronting the reader with the shock and extreme alienation induced by her exposure to the medical environment and to a devastating meeting with her surgeon after her double mastectomy, which signified her final break with western medicine. In the form of a short experimental film, I will look for the lost notion of trust as it plays in Acker's last story. I will employ a mixed visual approach creating a collage film in a way similar to the cut-up technique, appropriation, and repurposing employed by Acker in her novels. Following Acker's subversive stance towards identity, I will not offer a crystalized portrait of the last phase of a life, but will remix the pieces, play with possibilities, and return to the notion of trust, reassembling emotions and power relations in the realm of health care.

\section{SEARCHING FOR INFORMATION ON LOW BACK PAIN: TRUST AND DISTRUST OF INTERNET}

C Véron, M Santiago Delefosse. University of Lausanne, Switzerland

\subsection{6/bmjopen-2021-QHRN.33}

Background Patient information is a key element in the management of low back pain (LBP) and has taken a new dimension in the digital era. With the development of Internet, health information is no longer reserved to doctors but is accessible to people at all times. Online health information is thus redefining power relations between patients and healthcare professional. Few studies have investigated online information seeking in LBP, and fewer yet specifically with qualitative methods.

Aim We aimed to explore the experiences, perceptions and needs of people suffering from non-specific chronic LBP regarding online health information. The impact of Internet information seeking on the patient-healthcare professional relationship was also investigated.

Methods We conducted 21 semi-structured interviews with adults suffering from non-specific chronic LBP using an interview guide. Purposive sampling was used. Interviews were transcribed and analysed using thematic analysis.

Results Thematic analysis indicates that few people with chronic LBP actively use Internet to find health information. Most participants perceive indeed online information as unreliable and alarming. Some people have also difficulties finding relevant information. Hence, they mostly rely on their individual experience of pain as source of knowledge and seek medical advice. However, patients are globally unsatisfied with the lack of medical explanations and solutions for their pain and wish for more patient-centred care. They thus seek explanations and solutions outside of the medical world (self-management, complementary and alternative therapies, experience sharing) and occasionally seek specific back pain information on Internet.

Conclusions Although Internet provides quick access to health information, people with chronic LBP are suspicious of online information. Healthcare professionals remain an important source of reliable information but should better take into account patients' experiential knowledge to offer individualised care. Finally, focus groups with healthcare professionals will help to further understand how online information seeking transforms the patient-healthcare relationship.

\section{COVID-19, VACCINATION, AND TRUST: AN INTERVIEW STUDY}

J Vikse, V Nelson, K O'Doherty. University of Guelph, Canada

\subsection{6/bmjopen-2021-QHRN.34}

In addition to direct health threats of the COVID-19 pandemic, societies are experiencing significant harms and burdens associated with measures to mitigate the effects of the virus. In this context, a possible vaccine is perhaps the most highly regarded prospect to combat the novel coronavirus and enable societies to lift COVID related restrictions. Governments and other institutions around the world have invested large amounts of resources into the development, testing, and production capacity for several different vaccines. When vaccines become available, public health authorities will need 
information about the concerns and decision-making considerations of constituents. We outline here the key findings from interviews with residents of Ontario, Canada, $(n=40)$ in July and August of 2020 regarding their views, concerns, and intentions with respect to a prospective COVID-19 vaccine. In particular, participants expressed concern about the safety and efficacy of any prospective vaccine that is developed in a short timeframe, despite eagerness to eventually take it. Additionally, participants expressed considerations that, while not directly related to vaccines, nevertheless factored into their attitudes about accepting a possible COVID vaccination. These included how successful governments have managed COVID19 so far, existing relationships with healthcare providers, and how they have assessed their risk of contracting or becoming very ill from COVID-19. Trust in science, regulators, and governments will play a critical role in the successful deployment of a COVID-19 vaccine. Governments and public health institutions can take actions to earn trust. Implementing monitoring programs for long-term adverse effects would measure and potentially mitigate risk of unforeseen effects. Supports that provide financial and social stability during the wait for rigorously tested vaccines may increase trust in governments to act in the best interest of their constituents.

\section{HOW TRUST AND POWER RELATIONS MIGHT SHAPE THE WORK OF INCIDENT INVESTIGATORS IN HEALTHCARE SERVICES}

G Vilanova, J Sandall, A Xyrichis. King's College London, UK

\subsection{6/bmjopen-2021-QHRN.35}

Background Improving the quality of care in maternity services is a significant concern in the United Kingdom and a challenge for many other countries around the world. Little is known about the inner workings and interprofessional dynamics of patient safety teams which are responsible for incident investigations in healthcare services.

Objectives To develop an understanding of the patient safety team's identity as internal incident investigators, and how trust and power relations shape their work inside hospitals.

Method An ethnography carried between October 2019 and March 2020 in a large maternity hospital in Brazil. The researcher made use of non-participant observation, individual semi-structured interviews and institutional reading related to incident investigations. Fourteen professionals agreed to take part in this current study. Thematic analysis was used to identify themes and categories.

Results Eight major categories were identified: 'fear of conflicts', 'no jurisdiction and no boundaries of work', 'lowesteem feeling', 'not ready for including patients into investigations', 'invisible hierarchy position', 'educational identity', 'blurred expectations', 'manipulation of data'. All professionals' categories in this study highlighted broadly similar needs in terms of clarifying the investigator role and identity as a team. Participants also feared of being in trouble during an investigation, and it was not uncommon the practice of incident data manipulation. A key finding of this study relates to professionals perceived needs and how they would like to be supported during the incident investigations, contributing to the current evidence.

Conclusions This study provides insights into how fear and lack of identity influence the internal incident investigators work. The lack of identity as a team and the sense of powerlessness to establish jurisdiction of work led investigators to not trust in themselves and have a perceived sense of useless work when comparing what they do with what they expected they should be doing.

\section{6 'THE TRUTHFULNESS FACTOR': A DIMENSIONAL ANALYSIS OF MORAL CARE AND MATERNAL SUBSTANCE USE}

C Whitney. Stony Brook University School of Nursing, USA

\subsection{6/bmjopen-2021-QHRN.36}

Background Delivering quality maternal-child healthcare is compromised when clinicians moralize pregnant or lactating persons' actions. Clinicians are professionally charged with ensuring quality care delivery. However, they commonly moralize substance use and other similarly stigmatized actions during pregnancy and lactation. As a result, pregnant or lactating persons and their infants experience suboptimal health outcomes. Improving health outcomes in this population necessitates understanding how clinicians come to moralize substance use during pregnancy and lactation. Dimensional analysis in the mode of emergent fit, an interactionist qualitative mode of inquiry.

Objective This study aimed to uncover the circumstances under which clinicians moralize substance use in maternal-child symbiosis.

Methods Dimensional analysis in the mode of emergent fit was used as an interactionist method of inquiry. Fifteen semistructured interviews were conducted with maternal-child health clinicians and data were analyzed according to the method's analytic processes.

Results The findings of this emergent fit dimensional analysis form a situation specific theory, which reveals that clinicians moralize substance use in maternal-child symbiosis when perceived fractured trust in the caring relationship. These circumstances exist within the process of the Moral Energy Reflex, which is driven by the condition of 'The Truthfulness Factor' and results in the consequence of Reflection on Redirection. The condition, process, and consequence of the phenomenon are conceptually bounded within the context of Unacceptability Uncertainty. All of the dimensions of moralizing substance use during maternal-child symbiosis are understood through the perspective of Am I a 'Good Enough' Clinician?

Conclusion Understanding moralization as a process actively formed by the person moralizing and their perceptions of trust, provides important new insight into the clinical phenomenon of moral judgment. These findings suggest directions for future inquiry and offer implications for education, practice, and policy.

\section{$37 \quad$ PUBLIC TRUST IN HEALTHCARE SYSTEMS IN INDIA}

J Yadav. Center of Social Medicine and Community Health, Jawaharlal Nehru University, India

\subsection{6/bmjopen-2021-QHRN.37}

Background Trust in healthcare institutions plays a major role in public health as it reflects patients' compliance with the medical care system and better utilization of the resources 